\title{
Relationship of Apolipoprotein B Levels to the Number of Risk Factors for Metabolic Syndrome
}

\author{
Jacob J. Clarenbach, Scott M. Grundy, Natalia Palacio, and Gloria Lena Vega
}

\begin{abstract}
Low-density lipoprotein cholesterol (LDL-C) is the primary target of lipid-lowering therapy. However, all lipoproteins containing apolipoprotein B (apo B) appear to be atherogenic. Preferred targets of therapy therefore may include either the cholesterol in all apo B-containing lipoproteins (non-high-density lipoprotein cholesterol [non-HDL-C]) or total apo B itself. Apo B can be measured by three methods: chemically, by nuclear magnetic resonance (NMR), and by immunoassay. This study compares the first two methods as a function of the number of metabolic risk factors in patients with metabolic syndrome. Plasma lipid, lipoprotein cholesterol, and apo B levels were measured in 274 adults with varying numbers of metabolic syndrome components. Low-density lipoprotein (LDL) particle sizes were measured by gel electrophoresis and by NMR. Total apo B was estimated chemically and by conversion of NMR lipoprotein particle number, assuming one apo B molecule per lipoprotein particle. As the number of metabolic syndrome components increased, apo B rose by both chemical and NMR methods, but by chemical methods, increases were in the triglyceriderich fraction, whereas by NMR, they were in LDL. The correlation between total apo B measured by the two methods was only moderate $(r=.73)$. Further, non-HDL-C was more highly correlated with total apo B measured chemically than either LDL-C or total apo B by NMR. Non-HDL-C correlates highly with total apo B in patients with metabolic syndrome and had advantages as a target of therapy over LDL-C or NMR apo B.
\end{abstract}

Key words: apolipoprotein B, low density lipoprotein, metabolic syndrome, nuclear magnetic resonance

Currently, low-density lipoprotein cholesterol (LDL-C) is the primary target of lipid-lowering therapy, ${ }^{1}$ yet all apolipoprotein B (apo B)-containing lipoproteins, including triglyceride-rich lipoproteins (TGRLPs), appear to be atherogenic. ${ }^{2}$ For this reason, the National Cholesterol Education Program (NCEP) indicated that non-high-density lipoprotein cholesterol (non-HDL-C) is a secondary target of therapy, after

From the Center for Human Nutrition (J.J.C., S.M.G., N.P., G.L.V.), the Department of Clinical Nutrition (S.M.G., G.L.V.), the Department of Internal Medicine (S.M.G.), the Donald W. Reynolds Cardiovascular Research Center of the University of Texas Southwestern Medical Center at Dallas (S.M.G., G.L.V.), Dallas, TX, and the Veterans Affairs Medical Center at Dallas (S.M.G.), Dallas, TX.

Address correspondence to: Dr. Scott M. Grundy or Dr. Gloria Lena Vega, University of Texas Southwestern Medical Center, 5323 Harry Hines Blvd, Dallas, TX 75390-9052; e-mail: Scott.Grundy@utsouthwestern.edu; Gloria.Vega@ utsouthwestern.edu.

Journal of Investigative Medicine 2007;55:237-247.

DOI 10.2310/6650.2007.00004
LDL-C, in patients with elevated triglycerides. ${ }^{1}$ This accords with recent reports that non-HDL-C is a stronger predictor of coronary heart disease than is LDL-C. ${ }^{3-6}$ Other studies put the priority on total apo $\mathrm{B}$ as the preferred target of therapy. ${ }^{2}$ Moreover, measurement of low-density lipoprotein (LDL) particles, either LDL particle number or LDL particle size, may provide useful predictive information. ${ }^{7,8}$

In this article, we compare two methods for measurement of total apo B in patients with and without metabolic syndrome. ${ }^{9}$ One method measures total apo B chemically by adding apo B in LDL and in TGRLPs after ultracentrifugal separation. The other counts lipoprotein particles by nuclear magnetic resonance (NMR). Particle concentration can readily be converted to apo B concentration assuming one apo $B$ molecule for every LDL and TGRLP. The most widely used method for estimating total apo B is immunoassay. ${ }^{10}$ But immunoassay has the disadvantage of variable immunoreactivities of apo B in different lipoprotein subfractions and difficulties in standardization. ${ }^{11}$ If NMR apo B could be shown to be accurate, it could have an advantage over immunoassay. 


\section{Methods}

\section{Subjects}

Two hundred seventy-four adults from the Veterans Affairs Medical Center at Dallas participated in a cross-sectional study designed to quantify total apo $\mathrm{B}$ and its distribution among lipoprotein fractions as a function of the number of metabolic syndrome components. These components were defined by NCEP criteria. ${ }^{1,9}$ Subjects had clinical assessment, anthropometry, and blood drawn after a 12-hour fast for measurement of plasma lipids, lipoproteins, and apolipoproteins. The study was approved by our institutional review board.

\section{Laboratory Measurements}

Plasma total cholesterol, triglyceride, and highdensity lipoprotein cholesterol (HDL-C) levels were measured as previously reported. ${ }^{12}$ HDL-C was measured after precipitation of apo B-containing lipoproteins with dextran sulfate. Levels of very low-density lipoprotein (VLDL) + intermediate-density lipoprotein (IDL) cholesterol $(\mathrm{d}<1.019 \mathrm{~g} / \mathrm{mL})$ were determined after isolation of the lipoproteins by preparative ultracentrifugation. The mean total cholesterol recovery for all fractions after ultracentrifugation was $98.0 \pm 2.0 \%$. The cholesterol content of each fraction was adjusted for total percent recovery. LDL $(1.019-1.070 \mathrm{~g} / \mathrm{mL})$ was then isolated from the plasma infranatant of density $1.019 \mathrm{~g} / \mathrm{mL}$. Cholesterol and apo B were measured in the plasma fractions $\mathrm{d}<1.019 \mathrm{~g} / \mathrm{mL}$ and $\mathrm{d}=1.019 \mathrm{~g} /$ $\mathrm{mL}$ to $1.070 \mathrm{~g} / \mathrm{mL}$, and the ratio of cholesterol to apo B was calculated. The absolute level of LDL-C was calculated as the difference between total cholesterol minus the sum of cholesterol in VLDL + IDL of the $1.019 \mathrm{~g} / \mathrm{mL}$ supernatant adjusted for cholesterol recovery plus high density lipoproteins (HDLs) measured in plasma after dextran sulfate precipitation of non-HDL lipoproteins.

Apo B was measured chemically in isolated VLDL + IDL and LDL using the Markwell modification of the Lowry procedure and with bovine serum albumin (BSA) from the National Bureau of Standards as a reference standard. ${ }^{13}$ On the basis of published evidence, ${ }^{14,15}$ a chromogenicity factor of 1:1 between apo B and BSA was assigned. Absolute concentrations of total apo B were calculated as reported previously. ${ }^{13}$ LDL-apo B was calculated as the product of absolute LDL-C concentration estimated as detailed above and the ratio of cholesterol to apo B in isolated LDL. The coefficient of interassay variation for the Lowry method is $\leq 3.0 \%$.

LDL sizes were measured by polyacrylamine gel electrophoresis (Lipoprint, Quantimetrix Inc., Redondo
Beach, CA) as previously described. ${ }^{16}$ Lipoprotein particle concentrations in LDL and VLDL + IDL also were determined by NMR (courtesy of Liposcience, Raleigh, NC). ${ }^{17,18}$ This method uses curve fitting (spectral deconvolution) of the methyl lipid resonance envelope in plasma; the amplitude and shape of the resulting curve depend on amplitudes of the methyl resonances of the lipoprotein components. A curvefitting algorithm was used to determine concentrations of lipoproteins from the plasma spectrum. Mean LDL particle sizing by NMR is about $60 \AA$ lower than similar particles measured by the Lipoprint method. This difference can be explained by differences in reference methodology; NMR LDL particle sizes are referenced to particle diameters measured by electron microscopy, whereas gel electrophoresis is referenced to charged particles of standard size. ${ }^{18}$

To compare chemical and NMR methods, lipoprotein particle concentrations by NMR were converted to apo $\mathrm{B}$ by dividing reported particle concentrations by 55 . The molecular weight of apo B is $550,000 \mathrm{Da}$, and all lipoproteins in density ranges of LDL, IDL, and VLDL are assumed to have one apo B molecule per particle.

\section{Statistics}

Data are expressed as mean \pm SD. Independent variables that are not normally distributed were $\log$ transformed for data analyses. The means of apo B levels between methods were compared by one-way analysis of variance with an alpha value set at $<.05$. The Cochran-Armitage trend analyses were used to determine the trend of metabolic parameters with increasing risk factor numbers.

\section{Results}

Table 1 gives mean values for risk factors in current patients. In Table 2, lipoprotein-apo B levels and cholesterol to apo B ratios obtained by chemical methods are presented and are compared with apo B parameters obtained by NMR. Total apo B and VLDL + IDL apo B levels were significantly higher by chemical methods compared with NMR, whereas mean LDL-apo B concentrations were similar by the two methods. Cholesterol to apo B ratios were lower than NMR for VLDL + IDL and non-HDL-C by chemical methods but were similar for LDL.

In Table 3, apo B parameters are shown for men and for the limited number of women with and without metabolic syndrome. In men, total apo B levels were higher in those with metabolic syndrome by both methods, although the mean apo B concentrations were lower by NMR than by the chemical method. When 
Table 1 Subject Demographics $(N=274)$

\begin{tabular}{lcc}
\hline Parameter & Mean $\pm S D$ & Median \\
\hline Age $(\mathrm{yr})$ & $56 \pm 9$ & 57 \\
Body mass index $\left(\mathrm{kg} / \mathrm{m}^{2}\right)$ & $30.3 \pm 4.9$ & 30.1 \\
Waist circumference $(\mathrm{cm})$ & $103 \pm 13$ & 103 \\
Systolic blood pressure $(\mathrm{mm} \mathrm{Hg})$ & $139 \pm 18$ & 138 \\
Diastolic blood pressure $(\mathrm{mm} \mathrm{Hg})$ & $81 \pm 10$ & 81 \\
Hemoglobin A $\mathrm{A}_{1 \mathrm{c}}(\%)$ & $5.6 \pm 0.8$ & 5.5 \\
Glucose $(\mathrm{mg} / \mathrm{dL})$ & $100 \pm 23$ & 96 \\
Total cholesterol $(\mathrm{mg} / \mathrm{dL})$ & $214 \pm 41$ & 214 \\
Triglyceride $(\mathrm{mg} / \mathrm{dL})$ & $177 \pm 120$ & 151 \\
HDL-C $(\mathrm{mg} / \mathrm{dL})$ & $43 \pm 12$ & 41 \\
LDL-C $(\mathrm{mg} / \mathrm{dL})$ & $132 \pm 32$ & 132 \\
Non-HDL-C $(\mathrm{mg} / \mathrm{dL})$ & $171 \pm 41$ & 169 \\
\hline
\end{tabular}

HDL-C $=$ high-density lipoprotein cholesterol; LDL-C $=$ low-density lipoprotein cholesterol.

measured chemically, VLDL + IDL- apo B levels were significantly elevated in metabolic syndrome, whereas LDL-apo B levels were not. By NMR, VLDL-apo B levels were much lower in both groups than by chemical methods, and although the two methods gave similar LDL-apo B levels, those with metabolic syndrome had somewhat (and significantly) higher LDL-apo B levels than those without. The latter differences were not observed in the limited number of women with or without metabolic syndrome.

Correlation coefficients among different apo B and cholesterol parameters are presented in Table 4. By the chemical method, non-HDL-C and LDL-apo B were more highly correlated with total apo $\mathrm{B}$ than was LDL-C. By NMR, LDL-apo B was correlated extremely highly with total apo B because almost all of the apo B-containing lipoproteins are identified in the LDL fraction by this method. However, nonHDL-C was less strongly correlated when total apo B was measured by NMR than by the chemical method. LDL-apo B was more strongly correlated with LDL-C by the chemical method than by NMR.
Figure 1 shows the pattern of change in waist circumference, triglycerides, and HDL-C levels with increasing number of metabolic syndrome components. VLDL + intermediate-density lipoprotein cholesterol (IDL-C) levels rose steeply along with triglyceride levels with an increasing number of metabolic syndrome components (Figure 2); there was a parallel rise in VLDL + IDL-apo B by chemical methods, but a much smaller increase was observed with NMR. In contrast to VLDL + IDL-apo B, the chemical method showed no increase in LDL-C or LDL-apo B as the number of components increased, but a shallow but consistent rise in LDL-apo B was observed by NMR (Figure 3).

LDL particle sizes and LDL-C to apo B ratios fell progressively with the number of metabolic syndrome components (Figure 4). Mean LDL particle sizes as measured by Lipoprint were consistently higher than those measured by NMR, but a similar pattern of decline was noted. At least two factors contribute to the reduction in LDL particle size and LDL-C to LDL-apo B ratios with increasing metabolic components. These are higher triglycerides and lower HDL levels (Figure 5). In this figure, the slope for the relationship between LDL-C to LDL-apo B ratios and triglycerides was much steeper when LDL-apo B was measured by NMR compared with the chemical method. Indeed, by NMR, a portion of subjects had both higher and lower LDL-C to LDL-apo B ratios than observed by the chemical method. This finding raises the possibility that NMR identifies some LDLsized particles that have a density $<1.019 \mathrm{mg} / \mathrm{mL}$ and some LDL-sized particles that have a density $>1.07 \mathrm{mg} / \mathrm{mL}$. Further, Figure 5 shows that there is a significant correlation between HDL-C and LDL-C to LDL-apo B ratios.

Because of the strong relationship between nonHDL-C and total apo B levels $(r=.873)$, an equation was derived from our data that will allow for

Table 2 Levels of Lipoprotein-Apolipoprotein B and Ratios $(N=274)$

\begin{tabular}{lccccc}
\hline & \multicolumn{2}{c}{ NMR Method } & & & \multicolumn{2}{c}{ Chemical Method } \\
\cline { 2 - 3 } \cline { 5 - 6 } Parameter & Mean $\pm S D$ & Median & & Mean \pm SD & Median \\
\hline LDL-apo B (mg/dL) & $95 \pm 25$ & 95 & & $95 \pm 21$ & 94 \\
VLDL + IDL-apo B (mg/dL) & $7 \pm 3$ & 7 & & $25 \pm 14^{*}$ & 23 \\
Total apo B (mg/dL) & $101 \pm 27$ & 102 & & $120 \pm 27^{*}$ & 118 \\
LDL-C to LDL-apo B (ratio) & $1.45 \pm 0.36$ & 1.41 & & $1.40 \pm 0.18$ & 1.37 \\
VLDL + IDL-C to apo B (ratio) & $6.04 \pm 4.11$ & 5.09 & & $2.01 \pm 9.16^{*}$ & 1.43 \\
Non-HDL-C to total apo B (ratio) & $1.72 \pm 0.32$ & 1.68 & & $1.43 \pm 0.15^{*}$ & 1.40 \\
\hline
\end{tabular}

apo B = apolipoprotein B; HDL-C = high-density lipoprotein cholesterol; IDL = intermediate-density lipoprotein; IDL-C = intermediate-density lipoprotein cholesterol; LDL $=$ low-density lipoprotein; LDL-C $=$ low-density lipoprotein cholesterol; NMR $=$ nuclear magnetic resonance; VLDL $=$ very low-density lipoprotein.

*Significantly different from the NMR method; $p<.05$. 
Table 3 Levels of Apolipoprotein B in Men and Women with and without Metabolic Syndrome Measured by Two Methods

\begin{tabular}{|c|c|c|c|c|c|c|c|c|}
\hline \multirow[b]{3}{*}{ Parameter } & \multicolumn{4}{|c|}{ Men (Chemical Method) } & \multicolumn{4}{|c|}{ Men (NMR Method) } \\
\hline & \multicolumn{2}{|c|}{$<3 R F(\mathrm{n}=78)$} & \multicolumn{2}{|c|}{$\geq 3 R F(\mathrm{n}=171)$} & \multicolumn{2}{|c|}{$<3 R F(\mathrm{n}=78)$} & \multicolumn{2}{|c|}{$\geq 3 R F(\mathrm{n}=171)$} \\
\hline & Mean $\pm S D$ & Median & Mean $\pm S D$ & Median & Mean $\pm S D$ & Median & Mean $\pm S D$ & Median \\
\hline $\begin{array}{c}\text { LDL-apo B } \\
(\mathrm{mg} / \mathrm{dL})\end{array}$ & $94 \pm 19$ & 94 & $95 \pm 21$ & 94 & $86 \pm 24$ & 82 & $99 \pm 24^{*}$ & 97 \\
\hline $\begin{array}{c}\text { VLDL + IDL- } \\
\text { apo B } \\
(\mathrm{mg} / \mathrm{dL})\end{array}$ & $17 \pm 8$ & 16 & $30 \pm 15^{*}$ & 26 & $6 \pm 3$ & 6 & $7 \pm 3$ & 7 \\
\hline $\begin{array}{l}\text { Total apo B } \\
(\mathrm{mg} / \mathrm{dL})\end{array}$ & $111 \pm 23$ & 111 & $125 \pm 27^{*}$ & 124 & $93 \pm 26$ & 89 & $106 \pm 26^{*}$ & 104 \\
\hline $\begin{array}{l}\text { LDL-C to } \\
\text { LDL-B } \\
\text { (ratio) }\end{array}$ & $1.44 \pm 0.19$ & 1.44 & $1.36 \pm 0.17^{*}$ & 1.34 & $1.61 \pm 0.35$ & 1.54 & $1.34 \pm 0.29^{*}$ & 1.33 \\
\hline $\begin{array}{l}\text { VLDL + } \\
\text { IDL-C } \\
\text { to apo } \\
\text { B (ratio) }\end{array}$ & $1.39 \pm 0.20$ & 1.33 & $2.37 \pm 11.59^{*}$ & 1.47 & $4.53 \pm 2.03$ & 4.03 & $6.89 \pm 4.74^{*}$ & 5.72 \\
\hline $\begin{array}{l}\text { Non-HDL-C } \\
\text { to total apo } \\
\text { B (ratio) }\end{array}$ & $1.44 \pm 0.17$ & 1.42 & $1.41 \pm 0.14^{*}$ & 1.39 & $1.78 \pm 0.36$ & 1.68 & $1.68 \pm 0.27^{*}$ & 1.66 \\
\hline
\end{tabular}

\begin{tabular}{|c|c|c|c|c|c|c|c|c|}
\hline \multirow[b]{3}{*}{ Parameter } & \multicolumn{4}{|c|}{ Women (Chemical Method) } & \multicolumn{4}{|c|}{ Women (NMR Method) } \\
\hline & \multicolumn{2}{|c|}{$<3 R F(\mathrm{n}=15)$} & \multicolumn{2}{|c|}{$\geq 3 R F(\mathrm{n}=10)$} & \multicolumn{2}{|c|}{$<3 R F(\mathrm{n}=15)$} & \multicolumn{2}{|c|}{$\geq 3 R F(\mathrm{n}=10)$} \\
\hline & Mean $\pm S D$ & Median & Mean $\pm S D$ & Median & Mean $\pm S D$ & Median & Mean $\pm S D$ & Median \\
\hline $\begin{array}{c}\text { LDL-apo B } \\
(\mathrm{mg} / \mathrm{dL})\end{array}$ & $96 \pm 27$ & 94 & $93 \pm 17$ & 96 & $91 \pm 36$ & 80 & $90 \pm 19$ & 87 \\
\hline $\begin{array}{l}\text { VLDL + IDL- } \\
\text { apo B } \\
(\mathrm{mg} / \mathrm{dL})\end{array}$ & $16 \pm 11$ & 11 & $22 \pm 7$ & 21 & $6 \pm 5$ & 5 & $7 \pm 3$ & 8 \\
\hline $\begin{array}{l}\text { Total apo B } \\
(\mathrm{mg} / \mathrm{dL})\end{array}$ & $112 \pm 34$ & 112 & $115 \pm 18$ & 118 & $97 \pm 39$ & 81 & $96 \pm 20$ & 95 \\
\hline $\begin{array}{l}\text { LDL-C to } \\
\text { LDL-B } \\
\text { (ratio) }\end{array}$ & $1.58 \pm 0.17$ & 1.60 & $1.47 \pm 0.23$ & 1.45 & $1.77 \pm 0.51$ & 1.65 & $1.56 \pm 0.40$ & 1.46 \\
\hline $\begin{array}{l}\text { VLDL + IDL- } \\
\text { C to apo } \\
\text { B (ratio) }\end{array}$ & $1.43 \pm 0.21$ & 1.40 & $1.45 \pm 0.39$ & 1.31 & $4.76 \pm 2.53$ & 4.20 & $5.25 \pm 2.38$ & 4.53 \\
\hline $\begin{array}{l}\text { Non-HDL-C } \\
\text { to total apo } \\
\text { B (ratio) }\end{array}$ & $1.57 \pm 0.14$ & 1.58 & $1.47 \pm 0.18$ & 1.51 & $1.91 \pm 0.50$ & 1.73 & $1.79 \pm 0.34$ & 1.68 \\
\hline
\end{tabular}

apo B = apolipoprotein B; HDL-C = high-density lipoprotein cholesterol; IDL-C = intermediate-density lipoprotein cholesterol; LDL-C - lowdensity lipoprotein cholesterol; NMR = nuclear magnetic resonance; RF = risk factors; VLDL = very low-density lipoprotein.

*Significantly different from the group with $<3$ RF $(p<.05)$, measured by the same method.

estimation of total apo B levels based on non-HDL-C levels. This equation is:

$$
\left.\begin{array}{r}
\text { Total apo } \mathrm{B}= \\
\text { non-HDL-C }
\end{array} \text { (equation } 1\right)
$$

In our analysis of the data, we also found that the LDL-C to LDL-apo $\mathrm{B}$ ratio is the major factor reducing the correlation between non-HDL-C and total apo B levels. Given that both triglyceride and HDL-C levels are correlated with LDL-C to LDL-apo
$\mathrm{B}$ ratios (see Figure 5), it should be possible to improve on estimated apo B over the use of non-HDL-C alone. Multifactorial analysis revealed the following equation:

$$
\begin{aligned}
\text { Total apo } \mathrm{B}= & 9.695+0.590 \text { non-HDL-C } \\
& +4.146 \ln \text { triglyceride (equation } 2) \\
& -0.252 \mathrm{HDL}-\mathrm{C}
\end{aligned}
$$

Figure 6 shows correlations between measured total apo B (by the chemical method) and estimated total apo 


\begin{tabular}{|c|c|c|c|c|}
\hline & \multicolumn{2}{|c|}{ Chemical Method } & \multicolumn{2}{|c|}{ NMR Method } \\
\hline & Correlation Coefficient & p Value & Correlation Coefficient & $\mathrm{p}$ Value \\
\hline \multicolumn{5}{|l|}{ Total apo B vs } \\
\hline LDL-C & 0.61 & $<.0001$ & 0.56 & $<.0001$ \\
\hline LDL-apo B & 0.85 & $<.0001$ & 0.99 & $<.0001$ \\
\hline VLDL + IDL-apo B & 0.63 & $<.0001$ & 0.62 & $<.0001$ \\
\hline Non-HDL-C & 0.88 & $<.0001$ & 0.76 & $<.0001$ \\
\hline Total apo B (chemical vs NMR) & - & - & 0.73 & $<.0001$ \\
\hline LDL-apo B vs LDL-C & 0.84 & $<.0001$ & 0.55 & $<.0001$ \\
\hline
\end{tabular}

apo B = apolipoprotein B; HDL-C = high-density lipoprotein cholesterol; IDL = intermediate-density lipoprotein; LDL = low-density lipoprotein; LDL-C = low-density lipoprotein cholesterol; NMR = nuclear magnetic resonance; VLDL $=$ very low-density lipoprotein.

B by NMR from non-HDL-C (equation 1) and from non-HDL-C + triglyceride + HDL-C (equation 2). The weakest correlation was with total apo B estimated by NMR $(r=.73)$. On the other hand, the correlation between total apo B (chemical method) and non-HDL$\mathrm{C}$ was improved only modestly by the addition of triglyceride and HDL-C to multiple regression analysis compared with non-HDL-C alone.
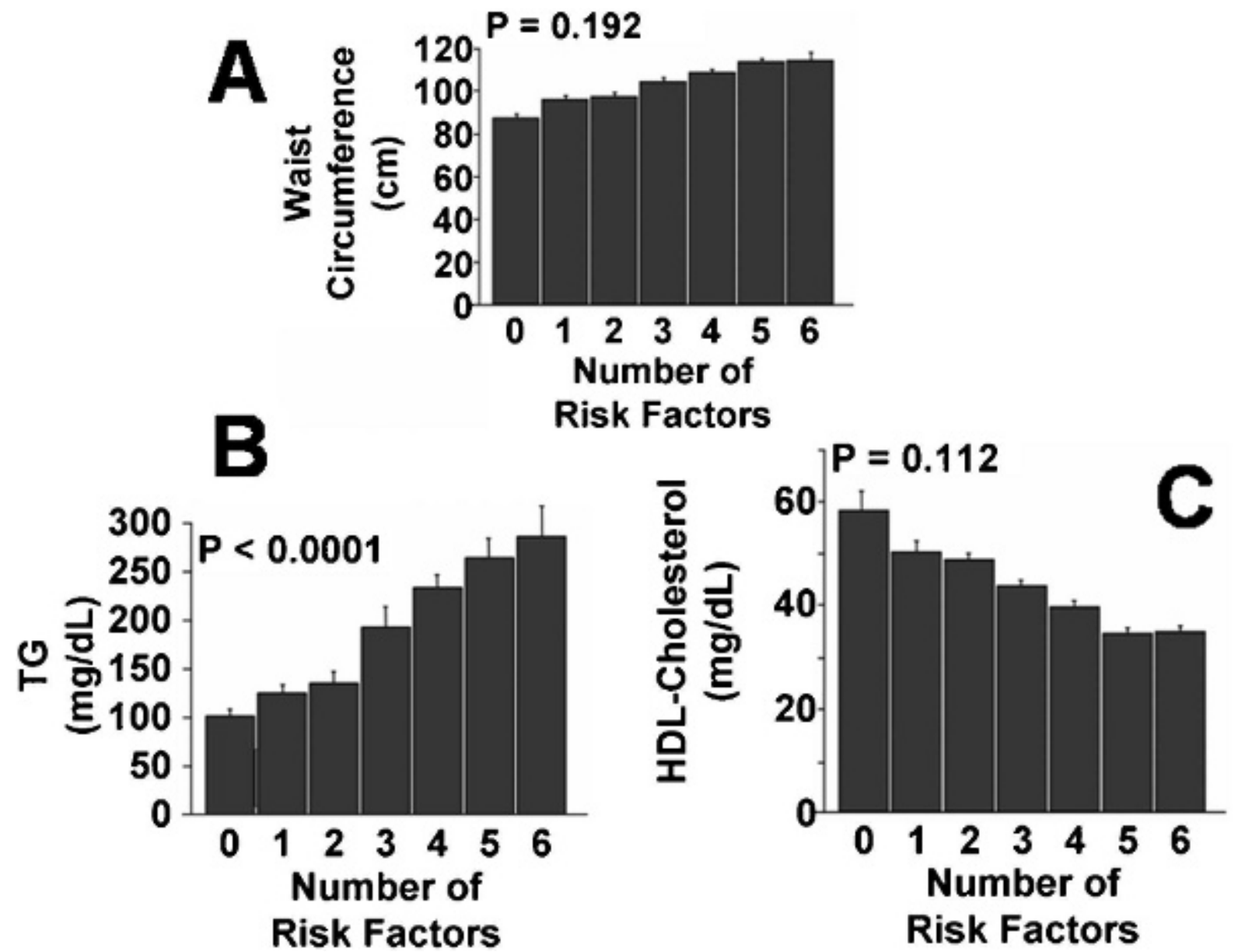

Figure 1 Waist circumference $(A)$, triglycerides $(\mathrm{TG})(B)$, and high-density lipoprotein (HDL)-cholesterol $(C)$ plotted against the number of metabolic risk factors of metabolic syndrome. Although there appeared to be a trend for a progressive increase in waist circumferences, formal trend analysis was not statistically significant. The same was true for the fall in HDL cholesterol. However, the trend for a rise in TG levels was highly significant. 

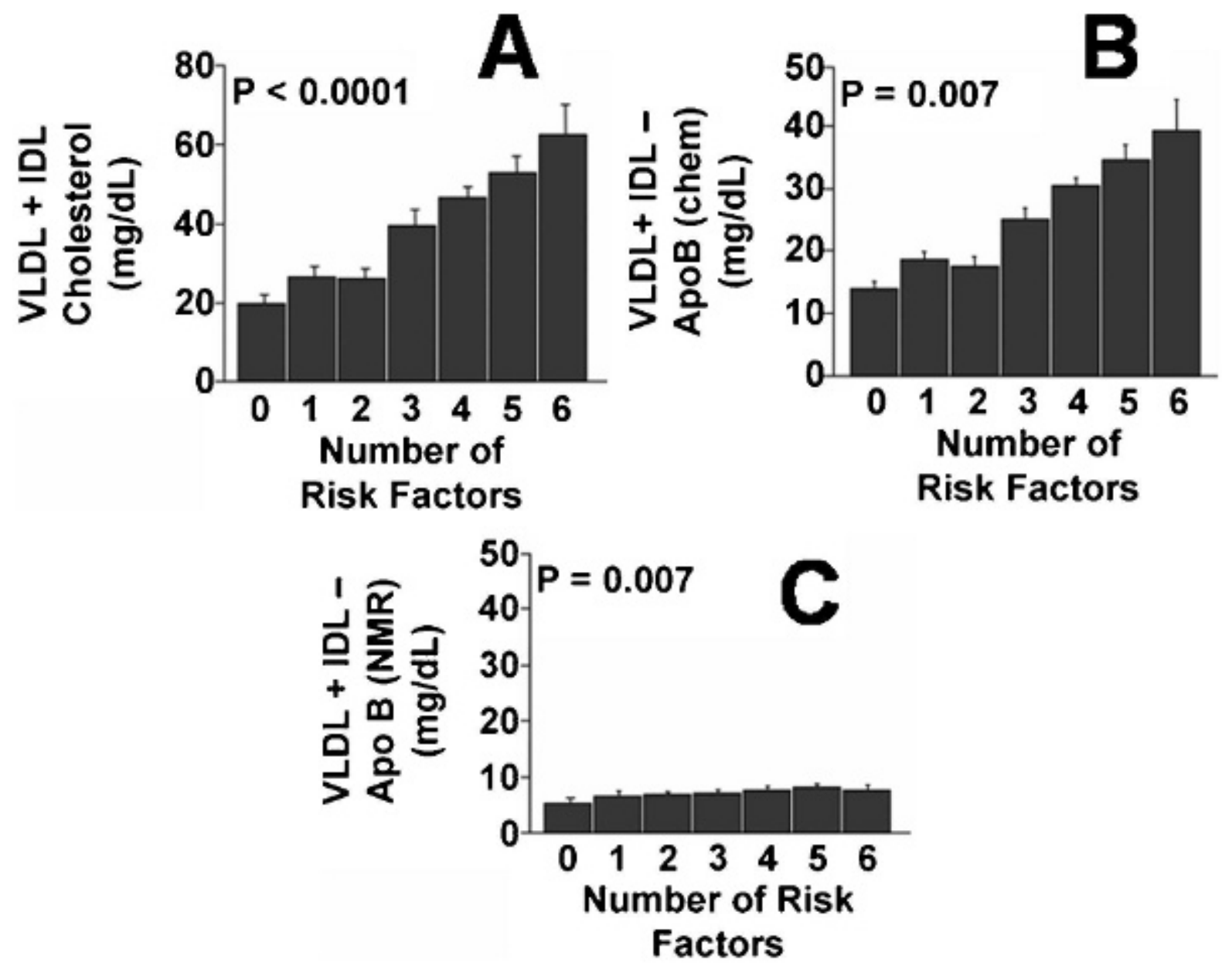

Figure 2 Plasma levels of very low-density lipoprotein (VLDL) + intermediate-density lipoprotein (IDL) cholesterol (A), VLDL + IDL apolipoprotein $B(A p o B)$ by the chemical method $(B)$, and VLDL + IDL-apo B by nuclear magnetic resonance (NMR) (C) are plotted against the number of metabolic risk factors. Trends for increases with an increasing number of risk factors were observed for all of these measurements.

\section{Discussion}

In patients with metabolic syndrome, several potential targets of therapy for elevated lipids exist. According to the NCEP, LDL-C is the primary target of lipid-lowering therapy. ${ }^{1}$ Both epidemiologic data and clinical trials point to LDL as the major atherogenic lipoprotein; and the cholesterol component of LDL is readily and accurately measured, inexpensive, and widely available in clinical laboratories. ${ }^{1}$ On the other hand, other apo B-containing lipoproteins, notably TGRLP, appear to carry atherogenic potential. ${ }^{1,19}$ In TGRLP, VLDL + IDL-C is one marker for atherogenic lipoproteins. Consequently, non-HDL-C (the sum of LDL + IDL + VLDL-C) is an alternative to LDL-C as a target of therapy, particularly for hypertriglyceridemia, ${ }^{1,9}$ and probably is a better predictor of major cardiovascular events. ${ }^{3-6,20}$ The NCEP recommended that non-HDL-C should be a secondary target of therapy, after LDL-C treatment, in patients with hypertriglyceridemia. ${ }^{1}$ Non-HDL-C carries the same advantages as LDL: wide availability, accuracy in measurement, and being relatively inexpensive, besides being measurable in the nonfasting state. Other investigators proposed that total apo B itself may be an even better predictor than either LDLC or non-HDL-C. ${ }^{2,21,22}$ Although both apo B and non-HDL-C encompass LDL + IDL + VLDL, total apo $\mathrm{B}$ precisely measures the number of atherogenic lipoprotein particles. The superiority of total apo B over non-HDL-C in prediction has not been found in all studies, but the concept that atherogenesis is more 


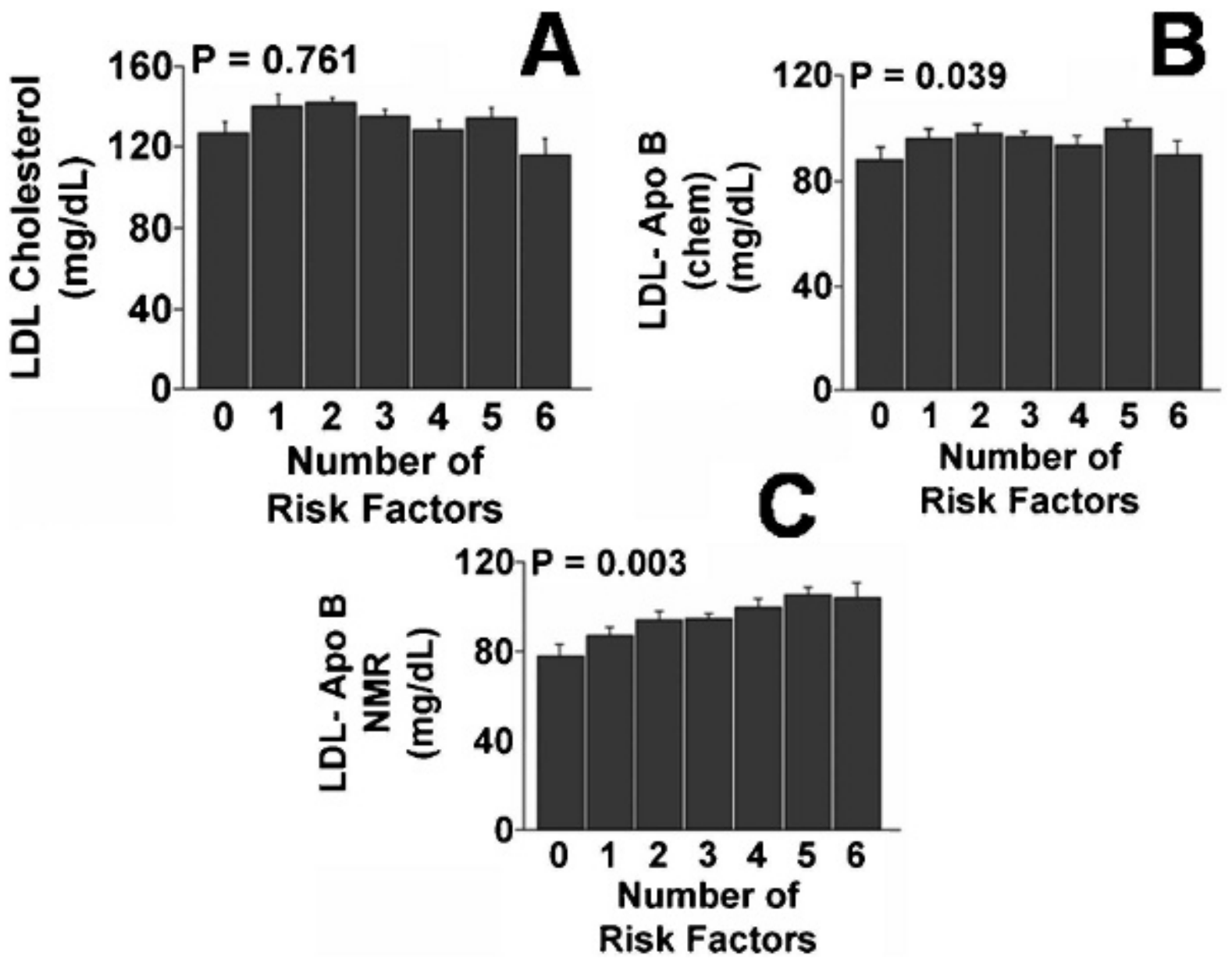

Figure 3 Plasma levels of low-density lipoprotein (LDL) cholesterol $(A)$, LDL-apolipoprotein $B$ (Apo B) by the chemical method $(B)$, and $L D L-a p o B$ by nuclear magetic resonance (NMR) $(C)$ are plotted against the number of metabolic risk factors. LDL-apo $B$ by both methods rose significantly with the number of risk factors, but LDL cholesterol did not.

dependent on the number of atherogenic particles than on their cholesterol content is attractive to many investigators.

On the other hand, the use of total apo B as a target of treatment has limitations. The usual method for measurement of total apo B is immunoassay. However, with immunoassay, different lipoprotein fractions can interact differently with measuring antibodies. ${ }^{11}$ Furthermore, no agreement exists on what the primary standard should be for apo B from which to estimate the absolute serum level of apo B. Thus, even if total apo B were to be a somewhat better predictor of cardiovascular disease risk than non-HDL$\mathrm{C}$, methodologic and availability issues currently stand in the way of its widespread use in clinical practice. In an effort to achieve a more accurate estimate of apo B, we employed a chemical technique that allows for a direct measure of apo B with a modified Lowry method. Another method has been introduced to estimate the lipoprotein particle number. This employs NMR; it calculates the lipoprotein particle number based on an NMR signal produced in serum. ${ }^{17,18}$ Several reports indicate that the lipoprotein particle number, as measured with NMR, correlates both cross-sectionally and prospectively with cardiovascular disease. ${ }^{7,10}$ Assuming that all lipoprotein particles that are LDL sized or greater contain apo B, the particle number obtained by NMR can be readily converted into a measure for LDL apo B and total apo B, based on the fact that each lipoprotein particle contains one molecule of apo B. Since the molecular weight of apo $\mathrm{B}$ is known with precision, it is possible to convert the apo B particle number into total apo B levels.

In patients with metabolic syndrome, ${ }^{9}$ atherogenic dyslipidemia has been reported to include high total apo B levels. ${ }^{19}$ In the present study, total apo B, as measured chemically, rose progressively with more metabolic syndrome components. The rise was mainly 

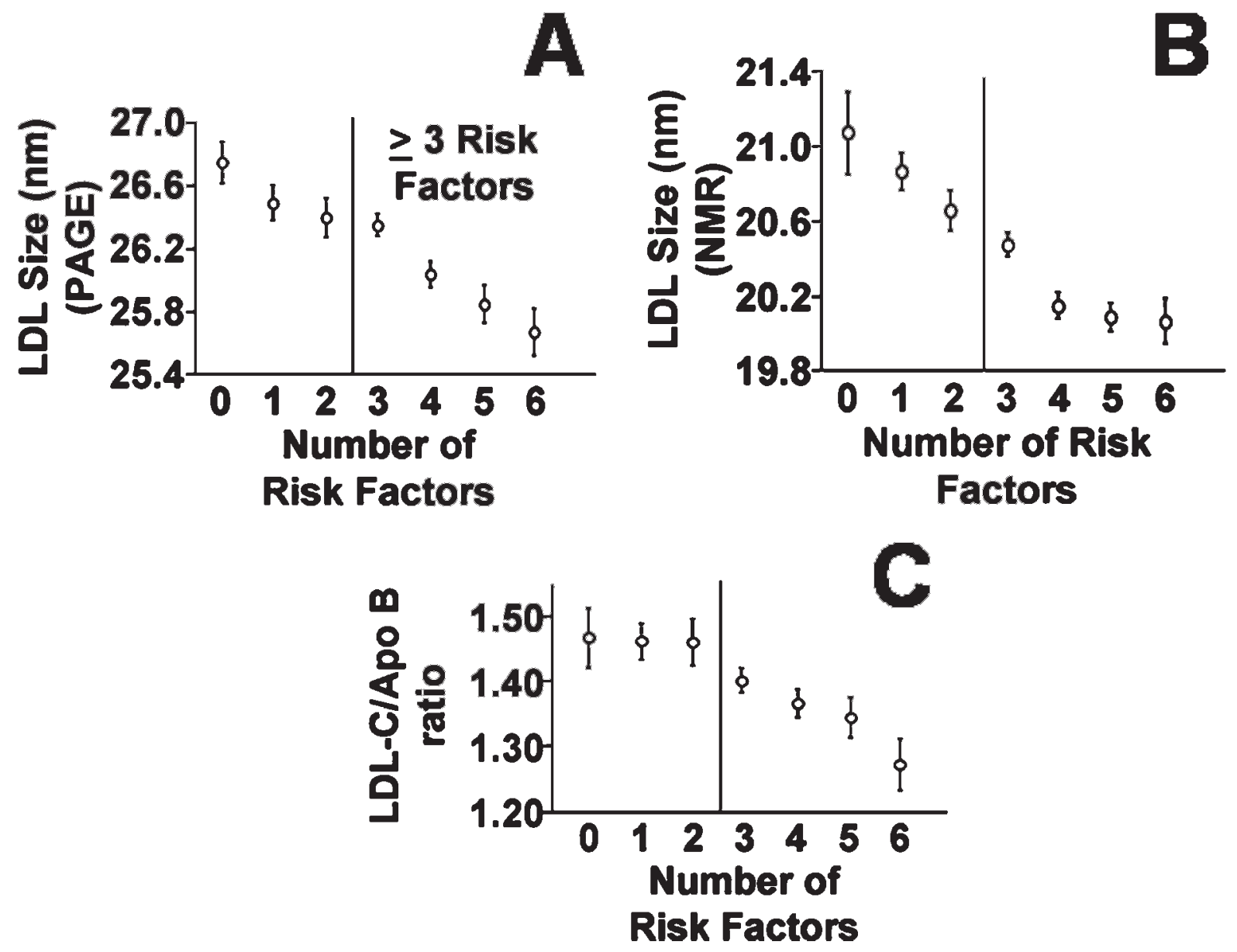

Figure 4 Low-density lipoprotein (LDL) particle size by polyacrylamide gel electrophoresis (PAGE) (A), LDL size by nuclear magnetic resonance (NMR) $(B)$, and LDL cholesterol (LDL-C) to apolipoprotein $B(A p o B)$ ratio $(C)$ plotted aginst the number of risk factors. All parameters fell progressively as the risk factor number increased.

in TGRLP, but not in LDL-apo B, and TGRLP-apo $\mathrm{B}$ paralleled the rises in triglycerides and VLDL + IDLC. In contrast, with the NMR method, most of the particles in LDL + IDL + VLDL appeared to be contained in the LDL fraction. A relatively small number of particles are detected in TGRLP. The mean levels of total apo B estimated by NMR were lower than by the chemical method. This difference could relate to the absolute standards used to estimate total apo B by the two methods.

In the current study, a discrepancy was also found between apo B content of TGRLP by NMR and by chemical methods. One possibility is that NMR underestimates particle concentration in TGRLP compared with established methods. Another is that some TGRLPs floating in the VLDL + IDL density range are LDL-sized particles. If so, they would be counted as LDL particles by NMR. This may account for the finding that LDL-apo B levels rose by NMR with an increasing number of metabolic syndrome components, whereas by the chemical method, the entire rise was in the VLDL + IDL fraction. Another factor that might contribute to a rise in LDL-apo B by NMR is that some particles that sink to the HDL density range also may be LDL sized but not contain apo B. This could account for the unusually low cholesterol to apo $\mathrm{B}$ ratios observed in some individuals; these ratios were uncharacteristically low for lipoproteins in the 1.019 to $1.07 \mathrm{~g} / \mathrm{mL}$ density range (see Figure 5).

Some of these differences could account for the discrepancy in lipoprotein-apo B distributions between the chemical method and NMR as the number of metabolic syndrome components increased. They cannot, however, explain the only moderate correlation $(r=.73)$ between total apo B measured by 

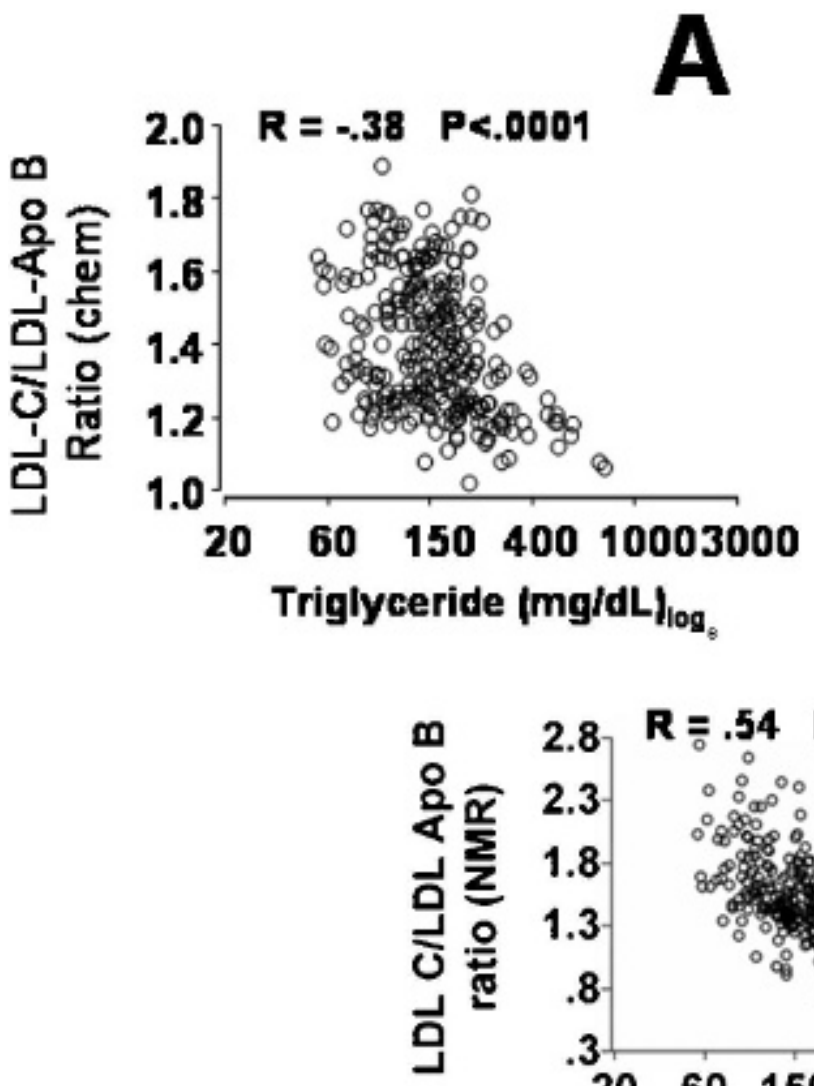

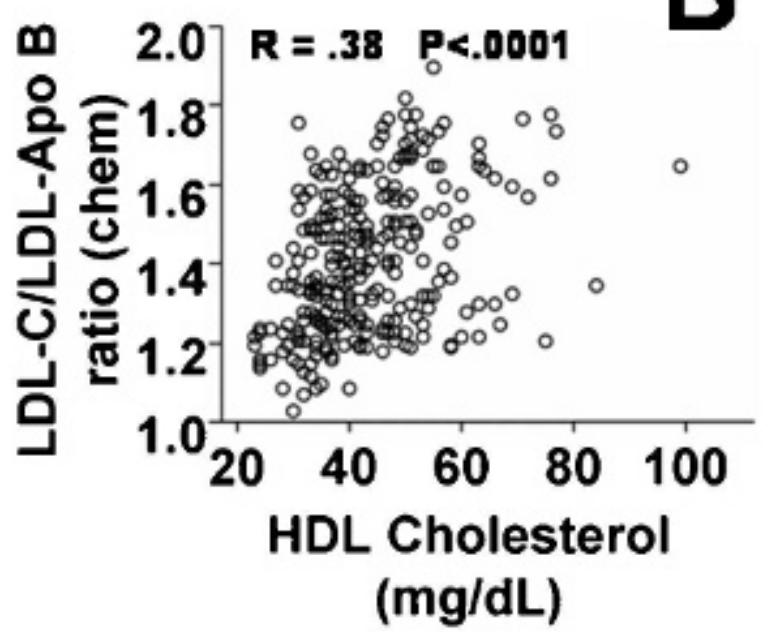

Figure $5 A$ and $B$, Ratios of low-density lipoprotein cholesterol (LDL-C) to low-density lipoprotein (LDL)-apolipoprotein B (Apo B) are plotted against log-transformed triglyceride and high-density lipoprotein (HDL) cholesterol. The same ratio obtained by nuclear magnetic resonance (NMR) is plotted against log-transformed triglycerides $(C)$. The range of ratios by the chemical method is much narrower by the chemical method $(A)$ than by NMR $(C)$. This difference presumably reflects the fact that the chemical method was carried out on samples isolated in a defined density range, whereas the NMR method was carried out on whole plasma, where the estimate depended on particle size and not on density range.

the chemical method and estimated by NMR. Given that the estimation of LDL particle number by NMR is based on a deconvolution of multiple curves derived from multiple sample analysis, it is not surprising that there is some discrepancy with an analysis in which a single measurement is made.

If treatment of atherogenic lipoproteins associated with the dyslipidemia of metabolic syndrome were to be limited to LDL, as is widely the case in current clinical practice, the question can be raised as to whether NMR provides a better measure of the atherogenicity of LDL than does LDL-C. At present, there is no simple method for the immunoassay of LDL-apo B. However, several reports indicate that the LDL particle concentration determined by NMR is more strongly correlated with cardiovascular events than is LDL-C. ${ }^{8,22}$ Whether this improvement in prediction is related to the inclusion of more LDLsized TGRLPs in the LDL fraction by NMR is uncertain but possible.

In spite of reports that total apo B may be a better predictor of chronic heart disease than non-HDL-C, the high correlation between estimated apo B (from non-HDL-C) and measured apo B (see Figure 5), a direct measurement of total apo B, cannot have much advantage over the estimated value as a target of therapy. Any slight advantage must be weighed against the lack of standardization of the immunoassay for apo $\mathrm{B}$, the increased cost of measurement added to routine lipoprotein analysis, and the lack of widespread availability of the assay. Estimation of total apo B (or LDL-apo B) by NMR has the same drawbacks listed 

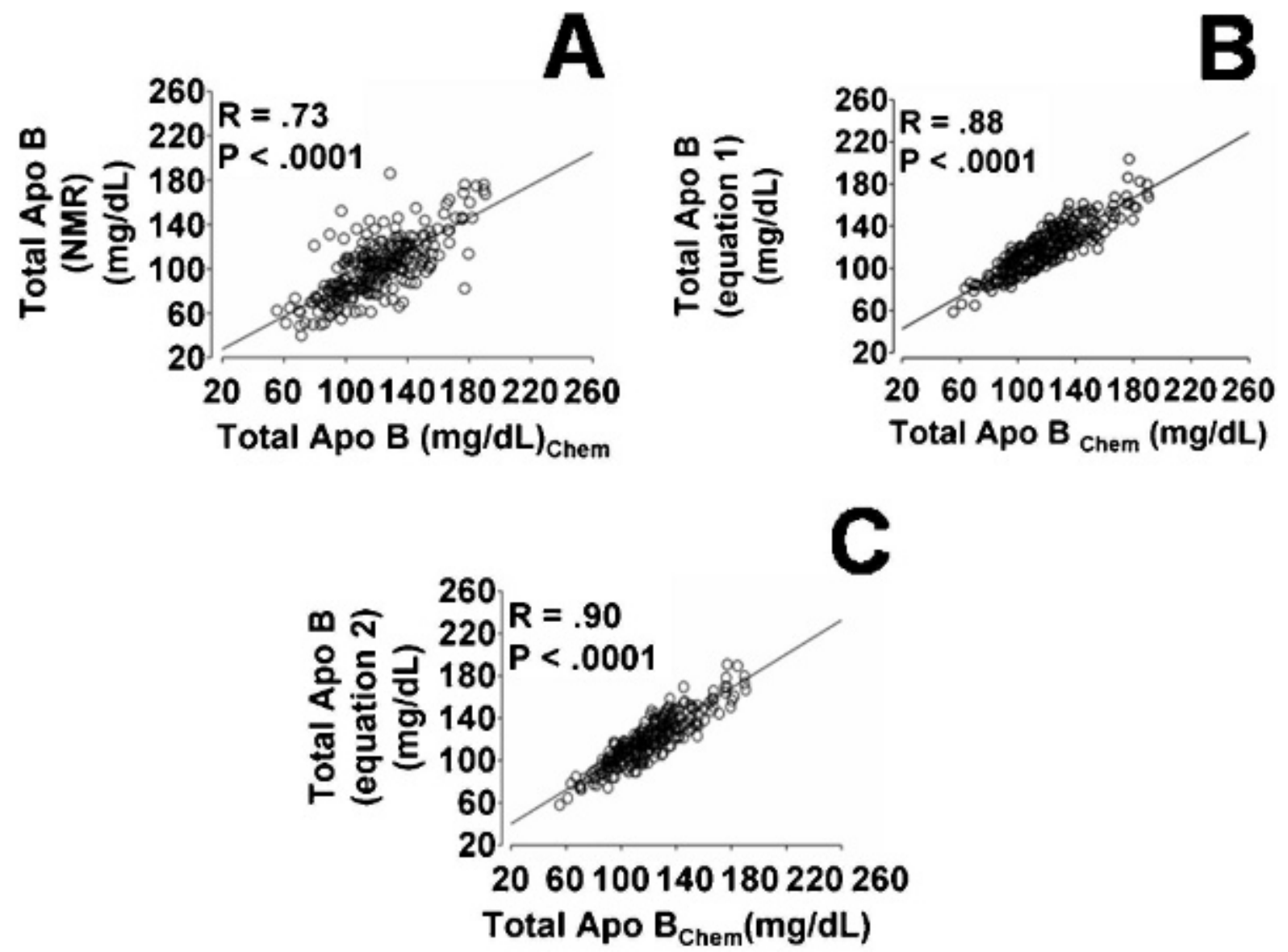

Figure 6 Comparisons of total apolipoprotein $B(A p o B)$ estimated by several methods: $(A)$ nuclear magnetic resonance $(\mathrm{NMR})$ versus chemical, $(B)$ from equation 1 versus chemical, and $(C)$ from equation 2 versus chemical. The improvement in the estimate of total apo B from equation 2 was small compared with equation 1.

for total apo B measurement. Before either immunoassay for total apo B or NMR assay for LDL particle concentration (or LDL-apo B) can be recommended for routine use in clinical practice, their superiority over non-HDL-C as a target of therapy must be documented from prospective studies or clinical trials.

\section{Acknowledgments}

We wish to express our appreciation for their excellent clinical assistance in the conduct of the study to Laura Caldwell, PA-C, Regina Strowd, RN, and Marjorie Whelan, RN. The excellent technical assistance in the analysis of the samples provided by Biman Pranamik, Kevin Vo, and Anh Nguyen is gratefully acknowledged. Beverley Huet, biostatistician at the General Clinical Research Center, was consulted for statistical analysis and study design. We also thank Mr. James Fries (Liposcience) for facilitating the nuclear magnetic analysis of the lipoproteins.

\section{References}

1. National Cholesterol Education Program (NCEP) Expert Panel on Detection, Evaluation, and Treatment of High Blood Cholesterol in Adults (Adult Treatment Panel III). Third Report of the National Cholesterol Education Program (NCEP) Expert Panel on Detection, Evaluation, and Treatment of High Blood Cholesterol in Adults (Adult Treatment Panel III) final report. Circulation 2002;106: 3143-421.

2. Barter PJ, Ballantyne CM, Carmena R, et al. Apo B versus cholesterol in estimating cardiovascular risk and in guiding therapy: report of the thirty-person/ten-country panel. Intern Med 2006;259:247-58.

3. Cui Y, Blumenthal RS, Flaws JA, et al. Non-high-density lipoprotein cholesterol level as a predictor of cardiovascular disease mortality. Arch Intern Med 2003;161:1413-9.

4. Jiang R, Schulze MB, Li T, et al. Non-HDL cholesterol and apolipoprotein B predict cardiovascular disease events among men with type 2 diabetes. Diabetes Care 2004;27: 1991-7. 
5. Liu J, Sempos C, Donahue R, et al. The joint distribution of non-HDL and LDL cholesterol and coronary heart disease risk prediction among individuals with and without diabetes. Diabetes Care 2005;28:1916-21.

6. Liu J, Sempos CT, Donahue RP, et al. Non-high-density lipoprotein and very-low-density lipoprotein cholesterol and their risk predictive values in coronary heart disease. Am J Cardiol 2006;98:1363-8.

7. Kuller L, Arnold A, Tracy R, et al. Nuclear magnetic resonance spectroscopy of lipoproteins and risk of coronary heart disease in the Cardiovascular Health Study. Arterioscler Thromb Vasc Biol 2002;22:1175-80.

8. Blake GJ, Otvos JD, Rifai N, Ridker PM. Low-density lipoprotein particle concentration and size as determined by nuclear magnetic resonance spectroscopy as predictors of cardiovascular disease in women. Circulation 2002;106: 1930-7.

9. Grundy SM, Cleeman JI, Daniels SR, et al, American Heart AssociationNational Heart, Lung, and Blood Institute. Diagnosis and management of the metabolic syndrome: an American Heart Association/National Heart, Lung, and Blood Institute scientific statement. Circulation 2005;112 2735-52.

10. Marcovina SM, Albers JJ, Kennedy $\mathrm{H}$, et al. International Federation of Clinical Chemistry standardization project for measurements of apolipoproteins A-I and B. IV. Comparability of apolipoprotein B values by use of International Reference Material. Clin Chem 1994;40:586-92.

11. Beghin L, Duhal N, Poulain P, et al. Measurement of apolipoprotein $\mathrm{B}$ concentration in plasma lipoproteins by combining selective precipitation and mass spectrometry. J Lipid Res 2000;41:1172-6.

12. Vega GL, Ma PT, Cater NB, et al. Effects of adding fenofibrate $(200 \mathrm{mg} /$ day $)$ to simvastatin $(10 \mathrm{mg} /$ day $)$ in patients with combined hyperlipidemia and metabolic syndrome. Am J Cardiol 2003;91:956-60.
13. Vega GL, Grundy SM. Quantitation of apolipoprotein B by chemical methods. Methods Enzymol 1996;263:6382.

14. Kane JP, Sata T, Hamilton RL, Havel J. Apoprotein composition of very low density lipoproteins in human serum. J Clin Invest 1975;56:1622-34.

15. Albers JJ, Lodge MS, Curtiss LK. Evaluation of a monoclonal antibody-based enzyme-linked immunosorbent assay as a candidate reference method for the measurement of apolipoprotein B-100. J Lipid Res 1989;30:1445-58.

16. Kazumi T, Kawaguchi A, Hozumi T, et al. Low density lipoprotein particle diameter in young, nonobese, normolipidemic Japanese men. Atherosclerosis 1999;142:113-9.

17. Otvos JD. Measurement of lipoprotein subclass profiles by nuclear magnetic resonance spectroscopy. In: Rifai $\mathrm{N}$, Warnick GR, Dominiczak MH, editors. Handbook of lipoprotein testing. Washington (DC): AACC Press; 2000. p. 609-23.

18. Jeyarajah EJ, Cromwell WC, Otvos JD. Lipoprotein particle analysis by nuclear magnetic resonance spectroscopy. Clin Lab Med 2006;26:847-70.

19. Krauss RM. Atherogenicity of triglyceride-rich lipoproteins. Am J Cardiol 1998;81:13B-7B.

20. Ridker PM, Rifai N, Cook NR, et al. Non-HDL cholesterol, apolipoproteins A-I and B100, standard lipid measures, lipid ratios, and $\mathrm{CRP}$ as risk factors for cardiovascular disease in women. JAMA 2005;294:326-33.

21. Sniderman AD, St Pierre AC, Cantin B, et al. Concordance/discordance between plasma apolipoprotein $\mathrm{B}$ levels and the cholesterol indexes of atherosclerotic risk. Am J Cardiol 2003;91:1173-7.

22. Walldius G, Jungner I, Holme I, et al. High apolipoprotein B, low apolipoprotein A-I, and improvement in the prediction of fatal myocardial infarction (AMORIS study): a prospective study. Lancet 2001;358:2026-33. 